\title{
Voltage sensitivity analysis to determine the optimal integration of distributed generation in distribution systems
}

\author{
Katherine Cabana ${ }^{1}$, John Candelo ${ }^{2}$, Rafael Castillo ${ }^{3}$, Emiro De-la-Hoz-Franco ${ }^{4}$ \\ ${ }^{1,4}$ Department of Computer Science and Electronics, Universidad de la Costa, Colombia \\ ${ }^{2}$ Department of Electrical and Automatic Energy. Universidad Nacional de Colombia Sede Medellin, Colombia \\ ${ }^{3}$ Department of Electrical and Electronic Engineering, Universidad del Norte, Colombia
}

\begin{tabular}{l} 
Article Info \\
\hline Article history: \\
Received Feb 22, 2018 \\
Revised Jul 19, 2018 \\
Accepted Sep 8, 2018 \\
\hline
\end{tabular}

\section{Keywords:}

Distributed generation

Distribution networks

Metaheuristic algorithms

Sensitivity analysis

Voltage magnitudes

\begin{abstract}
This paper presents a voltage sensitivity analysis with respect to the real power injected with renewable energies to determine the optimal integration of distributed generation (DG) in distribution systems (DS). The best nodes where the power injections improve voltages magnitudes complying with the constraints are determined. As it is a combinatorial problem, particle swarm optimization (PSO) and simulated annealing (SA) were used to change injections from $10 \%$ to $60 \%$ of the total power load using solar and wind generators and find the candidate nodes for installing power sources. The method was tested using the 33-node, 69-node and 118-node radial distribution networks. The results showed that the best nodes for injecting real power with renewable energies were selected for the distribution network by using the voltage sensitivity analysis. Algorithms found the best nodes for the three radial distribution networks with similar values in the maximum injection of real power, suggesting that this value maintains for all the power system cases. The injections applied to the different nodes showed that voltage magnitudes increase significantly, especially when exceeding the maximum penetration of DG. The test showed that some nodes support injections up to the limits, but the voltages increase considerably on all nodes.
\end{abstract}

Copyright (C) 2019 Institute of Advanced Engineering and Science. All rights reserved.

\section{Corresponding Author:}

Katherine Cabana,

Department of Computer Science and Electronics

Universidad de la Costa, CUC,

58 \# 55 - 66. Barranquilla, Colombia.

Email:kcabana@cuc.edu.co

\section{INTRODUCTION}

The integration of DG in distribution network has increased rapidly [1], since the possibility of generating power close to consumers, reducing power losses, increasing voltages, improving reliability, and others [2], [3]. However, the large penetration of electric sources brings stability problems [4], [5]. For this reason, the voltage stability must be study as the increasing penetration of renewable-energy demand high levels of reactive power in the power grid and voltage support is a major challenge[6]-[8].

According to [9], distribution networks have no stability problems in their normal design, but the integration of a large number of DG brings some stability issues. Some previous studies have determine that the connection of DG may affect the voltage stability in distribution systems [10], [9]. In [11], the researchers presented the particle swarm optimization (PSO) as an alternative to optimize a power injection model from DG, with the aim of maximizing voltage stability. In [12], a combination of evolutionary programming (EP) and PSO was presented to achieve convergence and accuracy of determining faster DG size and location. Furthermore, the authors in [13] have proposed the optimal placement, size and number of different types of DG units in distribution systems considering the voltage limits and the lines' transfer capacities, using the 
genetic algorithm (GA) as an optimization technique and the backward/forward sweep method (BFS). The authors in [14] investigated the evaluation of static voltage stability on IEEE 33-bus, PG\&E 69- bus and a real case with two stochastic DG units. In the literature, the studies presented focus on determining how the integration affects the voltage stability of the distribution network and the maximum value of integrating the generators [15]. However, some of these studies have focused on the optimal location of distributed generation to minimize power loss or cost functions, not analysing the voltage sensitivities of the nodes. And some studies uses metaheuristics applying the same objective functions to determine the best place for the power sources, but not other analysis such as voltage changes are considered to evaluate the possible integration of the renewable energy sources without affecting the operating conditions.

This paper focuses on determining the maximum integration of distributed generation in distribution networks by using the power flow iteration process integrated to the metaheuristic algorithms to search a better place for the power sources and the maximum power suported by the network without affecting the voltage conditions of the network. Because this is a large combinatorial problem, we used particle swarm optimization (PSO) and simulated annealing (SA) as the optimization techniques to determine the place and the size of DG. As the objective function we used the improvement of the voltage voltage profile in distribution networks. The approach is applied on IEEE 33-bus, IEEE 69-bus and IEEE 118-bus radial distribution system. To achieve this, Section 2 describes the methodology of the research. Section 3 presents the review and implementation of the methodology in a case study. Section 4 presents a brief discussion about distributed generation effects. Finally, the major contributions and conclusions of the papers are summarized.

\section{RESEARCH METHOD}

Figure 1 summarizes the method used in this research to determine the candidate nodes for installing DG. The proposed method starts reading the input data from the models of the distribution network. Then, an initial population is defined and evaluated. Finally, the location and size of DG is determined during the iteration of the algorithms.

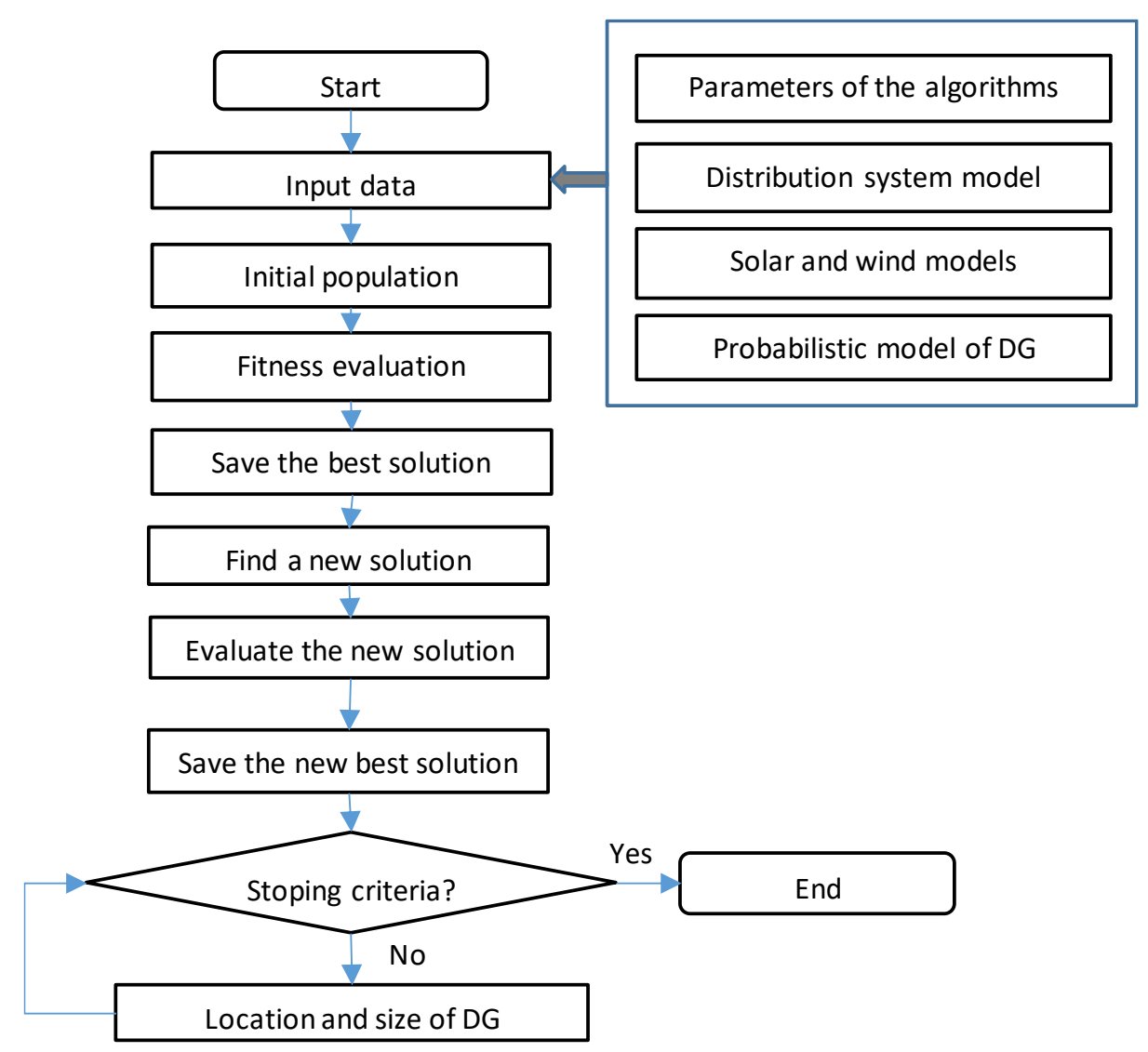

Figure 1. Flow chart of the methodology 


\subsection{Nodes for injecting power}

Finding the node to inject power in the distribution network is important for this study, because it defines the best place to install the DG, maintaining good operating conditions of the system under study. For this purpose, the following three stages were proposed in the analysis to determine the best nodes to inject power in the distribution networks [16].

Stage 1: distribution networks must be modelled to identify voltage sensitivities of different nodes when installing DG. A static model of each power plant under analysis is considered [17]. The load is modelled as constant value maintaining the same power factor and the main source was considered as the slack node.

Stage 2: the operating state of the distribution network is found, determining the voltage sensitivities of nodes with respect to the real power injected [18].

Stage 3: candidate nodes are selected using power flows and analyzed with voltage sensitivities before and after injecting real power. In this research, different scenarios of demand are used to identify weak nodes. Nodes are classified according to the voltage variations when the injection of real power increase.

\subsection{Scenarios for testing the method}

The following scenarios are considered to test the method and analyze the results:

1. Scenario 1. In this first scenario, no DG is considered for the simulation, being a base case to compare other results of the integration of solar and wind energy generation.

2. Scenario 2. In the second scenario, photovoltaic energy systems are integrated to the distribution network to determine the maximum power injection.

3. Scenario 3. In the third scenario, wind energy systems are integrated to the distribution network to determine the maximum power injection.

4. Scenario 4. In the fourth scenario, photovoltaic and wind energy systems are integrated to the distribution network to determine the maximum power injection.

\subsection{Considerations}

For testing the method, the following considerations are stated:

1. More than one generator can be installed at each node.

2. All DG units operate with a unitary power factor, to avoid interference with voltage control devices connected to the system [19], [20]. In addition, the power factor remains constant for all tests.

3. Wind speed and solar radiation have the same values for all the points where the generators can be installed.

4. Some researchers recommend that DG penetration levels are equal to or less than $30 \%$ of the maximum load [21]. However, in this study it is up to $60 \%$. The increasing power steps are defined as $0,10,20,30$, 40,50 , and $60 \%$.

5. The models of the elements proposed in [22] are used in this research.

6. Load is modelled for the four seasons of the year, as considered in other studies [22]. The power demand of each distribution network is considered as the peak value.

7. Solar radiation and wind speed are modeled using the Beta and Weibull probability density functions, respectively, as considered in other studies [22], [23].

8. DG units are installed on a given node and the voltage changes are monitored.

9. Each generator supplies a constant power of 4,5MW, with unity power factor.

10. The minimum and maximum voltage values for all the distribution networks were defined as Vmin $=0.9$ p.u. and $V \max =1.1$ p.u, respectively.

\subsection{Load model}

Table 1 presents the load profile, as percentages of the annual maximum load [22]. Annual maximum load demand is 16.18 MVA. Data is used to model solar radiation and wind speed with the Beta and Weibull probability functions, respectively. 
Table 1. Data Considered for the Loads of the Distribution Network [22]

\begin{tabular}{lllll}
\hline Hours & Winter & Spring & Summer & Fall \\
\hline $12-1$ am & 0.4757 & 0.3969 & 0.64 & 0.3717 \\
$1-2$ & 0.4473 & 0.3906 & 0.6 & 0.3658 \\
$2-3$ & 0.426 & 0.378 & 0.58 & 0.354 \\
$3-4$ & 0.4189 & 0.3654 & 0.56 & 0.3422 \\
$4-5$ & 0.4189 & 0.3717 & 0.56 & 0.3481 \\
$5-6$ & 0.426 & 0.4095 & 0.58 & 0.3835 \\
$6-7$ & 0.5254 & 0.4536 & 0.64 & 0.4248 \\
$7-8$ & 0.6106 & 0.5355 & 0.76 & 0.5015 \\
$8-9$ & 0.6745 & 0.5985 & 0.87 & 0.5605 \\
$9-10$ & 0.6816 & 0.6237 & 0.95 & 0.5841 \\
$10-11$ & 0.6816 & 0.63 & 0.99 & 0.59 \\
$11-2$ pm & 0.6745 & 0.6237 & 1 & 0.5841 \\
$12-1$ & 0.6745 & 0.5859 & 0.99 & 0.5487 \\
$1-2$ & 0.6745 & 0.5796 & 1 & 0.5428 \\
$2-3$ & 0.6603 & 0.567 & 1 & 0.531 \\
$3-4$ & 0.6674 & 0.5544 & 0.97 & 0.5192 \\
$4-5$ & 0.7029 & 0.567 & 0.96 & 0.531 \\
$5-6$ & 0.71 & 0.5796 & 0.96 & 0.5428 \\
$6-7$ & 0.71 & 0.6048 & 0.93 & 0.5664 \\
$7-8$ & 0.6816 & 0.6174 & 0.92 & 0.5782 \\
$8-9$ & 0.6461 & 0.6048 & 0.92 & 0.5664 \\
$9-10$ & 0.5893 & 0.567 & 0.93 & 0.531 \\
$10-11$ & 0.5183 & 0.504 & 0.87 & 0.472 \\
$11-2$ am & 0.4473 & 0.441 & 0.72 & 0.413 \\
\hline
\end{tabular}

\subsection{Solar model}

Solar radiation was modeled using the beta probability density function [22], [23], as shown in (1). Where $f_{b}(S)$ is the beta probability density function, $\mathrm{S}$ is the solar radiation in $\mathrm{kW} / \mathrm{m} 2$, considering that $0 \leq S \leq 1$. $\alpha$ and $\beta$ are parameters of the distribution function, considering that $\alpha>0$ and $\beta>0$.

$$
f_{b}(S)=\left\{\frac{\Gamma(\alpha+\beta)}{\Gamma(\alpha) \Gamma(\beta)} * S^{(\alpha-1)} *(1-S)^{(\beta-1)}\right.
$$

Parameter $\beta$ can be calculated using (2). Where $\mu$ is the mean distribution and $\sigma$ is the standard deviation of the distribution function.

$$
\beta=(1-\mu) *\left(\frac{\mu *(1+\mu)}{\sigma^{2}}-1\right)
$$
shown in (3).

Parameter $\sigma$ can be calculated using the average distribution parameter $\mu$ and the parameter $\beta$, as

$$
\sigma=\frac{\mu \beta}{1-\mu}
$$

\subsection{Wind model}

Wind speed variations can be described using the Weibull probability density function as shown in (4). Where $k$ is a shape parameter and $c$ is a scale parameter. When $k$ is equal to 2 , the probability density function is called Rayleigh $f_{w}(v)$ as shown in (5). Parameter $\beta$ was consider equal to 2.02 and parameter $\alpha$ equal to 9 [24], [25]. The scale parameter of the Rayleigh probability density function can be approximated as $c=1.128 * V_{m}$.

$$
\begin{aligned}
& f_{w}(v)=\frac{k}{c}\left(\frac{v}{c}\right)^{k-1} \operatorname{EXP}\left[-\left[\frac{v}{c}\right]^{k}\right] \\
& f_{r}(v)=\left(\frac{2 v}{c^{2}}\right) \operatorname{EXP}\left[-\left[\frac{v}{c}\right]^{2}\right]
\end{aligned}
$$




\subsection{Problem formulation}

The general model of the power system can be represented by the function $f(x, \lambda)$, as shown in (6). Where $x$ represents the state variables and $\lambda$ the load factor.

$$
f(x, \lambda)=0
$$

When the load increases, the system can suffer variations in stress levels. The variation in real and reactive power can be represented as shown in (7) and (8) [26]. Where $P_{i}$ and $Q_{i}$ represent the real and reactive power of the node $i$ after changing $\lambda$, respectively. $P_{0, i}$ and $Q_{0, i}$ are the initial real and reactive power of the node $i$, respectively. $K_{p, i}$ and $K_{q, i}$ are vectors that indicate the increasing power of node i, and $\Delta \lambda$ represents the variation of the load.

$$
\begin{aligned}
& P_{i}=P_{0, i}\left(1+K_{p, i} \cdot \Delta \lambda\right) \\
& Q_{i}=Q_{0, i}\left(1+K_{q, i} \cdot \Delta \lambda\right)
\end{aligned}
$$

The real and reactive power values of each node $i$, can be calculated as shown in (9) and (10), respectively. Where $n$ is the number of nodes, $\left|V_{i}\right|$ represents the voltage magnitude of the node $i, \delta_{i}$ represents the voltage angle of the node $i,\left|Y_{i j}\right|$ is the admittance magnitude of the element $(\mathrm{i}, \mathrm{j})$ and $\theta_{i j}$ is the impedance angle of the element $(i, j)$.

$$
\begin{aligned}
P_{i} & =\sum_{j=1}^{n}\left|V_{i}\right|\left|V_{j}\right|\left|Y_{i j}\right| \cos \left(\theta_{i j}-\delta_{i}+\delta_{j}\right) \\
Q_{i} & =\sum_{j=1}^{n}\left|V_{i}\right|\left|V_{j}\right|\left|Y_{i j}\right| \operatorname{sen}\left(\theta_{i j}-\delta_{i}+\delta_{j}\right)
\end{aligned}
$$

The real power changes of the different generators can be modelled by the expression presented in (11). Where $P_{G 0}$ the initial real power of each generation unit and $\lambda$ represents the power changing parameter. The variation of $\lambda$ is performed between zero (charge nominal system) and the maximum value of convergence [26].

$$
P_{G}=(1+\lambda) P_{G 0}
$$

The space of $(1+\lambda)$ variation in this research is limited between 0.5 and 1.5 times the load base. The increase in the level of charge is carried out with same value of $\lambda$, for all nodes.

\subsection{Objective function}

The objective function is defined to increase the generation at different nodes according to the voltage magnitudes of the network, as shown in (12). Where $V_{l}$ is the voltage at the selected node of the current scenario. $V_{\text {lbase }}$ is the voltage of the load node in the previous scenario. Where a high value of $V_{M}$ indicates an excellent location of DG in terms of the voltage magnitudes. At the maximum voltage values, the real or reactive powers are maximized [27].

$$
\text { Maximize } V_{M}=\frac{V_{l}}{\left[1-\left(V_{l}-V_{\text {lbase }}\right)\right]}
$$

\subsection{Electrical constraints}

The real power generated at node i, $P_{i}$, must be limited by the maximum and minimum value, as shown in (13). Where $P_{i, \min }$ and $P_{i, \max }$ represent the maximum and minimum real power limits generated at node $\mathrm{i}$, respectively.

$$
P_{i, \min } \leq P_{i} \leq P_{i, \max } i=(m+1),(m+2), \ldots, n
$$

The reactive power generated at node i, $Q_{i}$, must be restricted by the maximum and minimum value, as shown in (14). Where $Q_{i, \min }$ and $Q_{i, \max }$ represents the maximum and minimum reactive power limits generated at node $i$, respectively. 


$$
Q_{i, \min } \leq Q_{i} \leq Q_{i, \max } i=(m+1),(m+2), \ldots, n
$$

Voltage magnitude, $V_{i}$, of each node must be limited according to the maximum and minimum values, as presented in (15). Where $V_{i, \min }$ and $V_{i, \max }$ represents the maximum and minimum voltage magnitude limits of the node $i$, respectively. The slack node is assumed to have a voltage magnitude of 1 p.u.

$$
V_{i, \min } \leq V_{i} \leq V_{i, \min }
$$

\subsection{Test cases and simulations}

Three radial distribution systems were selected to test the method [28]-[31]. The 33-node radial distribution network [28], [29] has 33 nodes, 32 lines, 1 main source, and 32 loads. The total load of the network is $3715 \mathrm{~kW}$ and $2300 \mathrm{kVAr}$ and the total power supply of $3926 \mathrm{KW}$ and $2443 \mathrm{kVAr}$. The 69 -node radial distribution network [28]-[30] has 69 nodes, 68 lines, 1 main source, and 49 loads. The total load of the network is $4014 \mathrm{~kW}$ and $2845 \mathrm{kVAr}$ and the total generation of $4265 \mathrm{~kW}$ and $2957 \mathrm{kVAr}$. And finally, the 118-node radial distribution network [31] has 118 nodes, 117 lines, 1 main source, and 117 loads. The total load of the network is $22709 \mathrm{~kW}$ and $17041 \mathrm{kVAr}$ and the total generation of $24000 \mathrm{~kW}$ and $18019 \mathrm{kVAr}$.

\section{RESULTS AND ANALYSIS}

\subsection{Node selection}

Table 2 shows the results obtained when locating and sizing different generators in the distribution network with the objective function studied. The first column is the distribution network test case, the second column is the node selected for installing DG, and the other columns correspond to the results obtained with the algorithm testing the four scenarios. The higher power injection is obtained for the nodes away from the main source. Additionally, from the table we can conclude that the algorithms find the same solutions, but SA have a large time to converge for the solution compared to the PSO. The number of iterations of the SA is greater than the used with the PSO. The voltage sensitivity analysis found with PSO and SA presented a correlation coefficient of 0.9 , indicating a strong and positive correlation between the data obtained by each algorithm.

\begin{tabular}{|c|c|c|c|c|c|c|c|c|c|c|c|}
\hline \multirow{3}{*}{ Power System } & \multirow{3}{*}{ Nodes } & \multicolumn{10}{|c|}{ Scenario (MW) } \\
\hline & & \multicolumn{2}{|c|}{1} & \multicolumn{2}{|c|}{2} & \multicolumn{2}{|c|}{3} & \multicolumn{4}{|c|}{4} \\
\hline & & PSO & SA & PSO & SA & PSO & $\mathrm{SA}$ & & & \multicolumn{2}{|c|}{ SA } \\
\hline \multirow{3}{*}{ IEEE 33} & 29 & 0 & 0 & 1.1 & 1.1 & 1.1 & 1.1 & \multicolumn{2}{|c|}{0.0} & \multirow{2}{*}{\multicolumn{2}{|c|}{$\begin{array}{l}0.0 \\
0.0\end{array}$}} \\
\hline & 30 & 0 & 0 & 0.0 & 0.0 & 0.0 & 0.0 & \multicolumn{2}{|c|}{0.0} & & \\
\hline & 32 & 0 & 0 & 4.4 & 4.4 & 2.5 & 2.5 & 3.48 & 3.48 & 3.48 & 1.2 \\
\hline \multirow{3}{*}{ IEEE 69} & 19 & 0 & 0 & 0.0 & 0.0 & 1.6 & 1.2 & \multicolumn{2}{|c|}{0.0} & \multicolumn{2}{|c|}{0.0} \\
\hline & 25 & 0 & 0 & 2.2 & 2.2 & 0.0 & 0.0 & \multicolumn{2}{|c|}{0.0} & \multicolumn{2}{|c|}{0.0} \\
\hline & 68 & 0 & 0 & 4.8 & 4.5 & 2.92 & 2.92 & 3.2 & 3.2 & 3.2 & 2.2 \\
\hline \multirow{3}{*}{ IEEE 118} & 21 & 0 & 0 & 3.78 & 3.78 & 0.0 & 0.0 & \multirow{2}{*}{\multicolumn{2}{|c|}{0.0}} & \multicolumn{2}{|c|}{0.0} \\
\hline & 22 & 0 & 0 & 0.0 & 0.0 & 1.1 & 1.1 & & & \multicolumn{2}{|c|}{0.0} \\
\hline & 117 & 0 & 0 & 9.57 & 8.57 & 4.16 & 4.16 & 4.36 & 4.36 & 4.36 & 1.1 \\
\hline
\end{tabular}

Table 2. Location and Size of DG with PSO and SA

Figure 2 shows the voltage sensitivity analysis when the power injected varies from $10 \%$ to $60 \%$ of the total load. When the power injection exceeds the $30 \%$, the voltage sensitivity values increase and separate from the initial values. The voltages have an exponential increase and the power flow shows that some nodes are overloaded. The simulations show a similar result obtained in previous results related to not exceed $30 \%$ of the power load [16], [21]. 


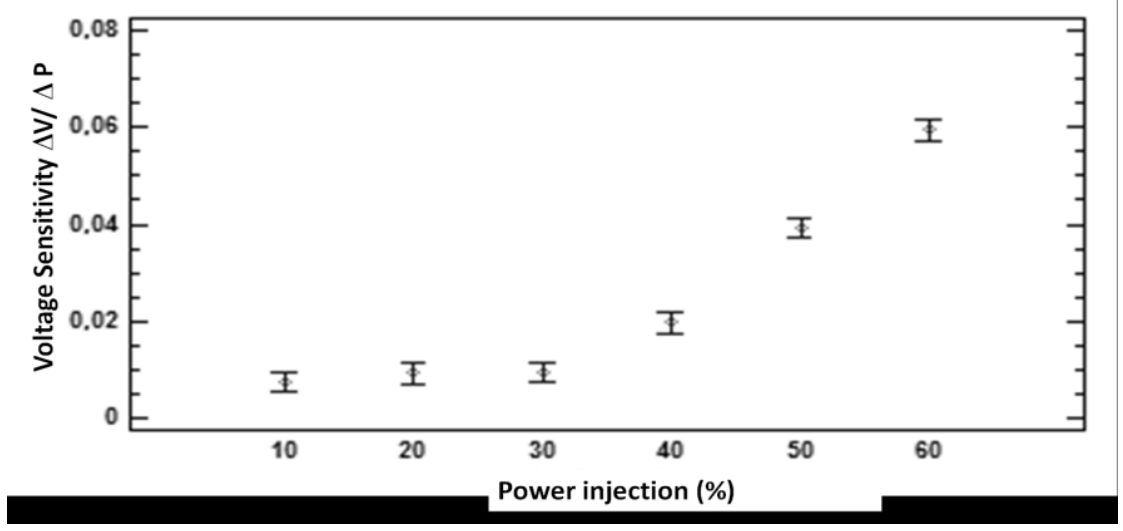

Figure 2. Voltage sensitivity with different power injection

\subsection{Sensitivity analysis of the 33-node test case}

Figure 3 presents the voltage sensitivity analysis of the 33-node radial distribution network. The real power was injected changing from $10 \%$ to $60 \%$ of the total load in steps of $10 \%$. The axis y represents the change in voltage magnitudes with respect to the change in real power. The axis $\mathrm{x}$ represents the node of the distribution network. When the real power injection reaches $40 \%$, the voltage changes significantly. The changes in voltage represents a large variation for all nodes of the distribution network. This result confirms the maximum levels of DG penetration for the $30 \%$ of the maximum load [21]. Nodes selected by the algorithms $(29,30$ and 32) are the most sensitive of the network, changing voltages significantly. Furthermore, a node randomly selected (node 6) shows that the maximum percentage has a different behavior in voltages of all nodes.

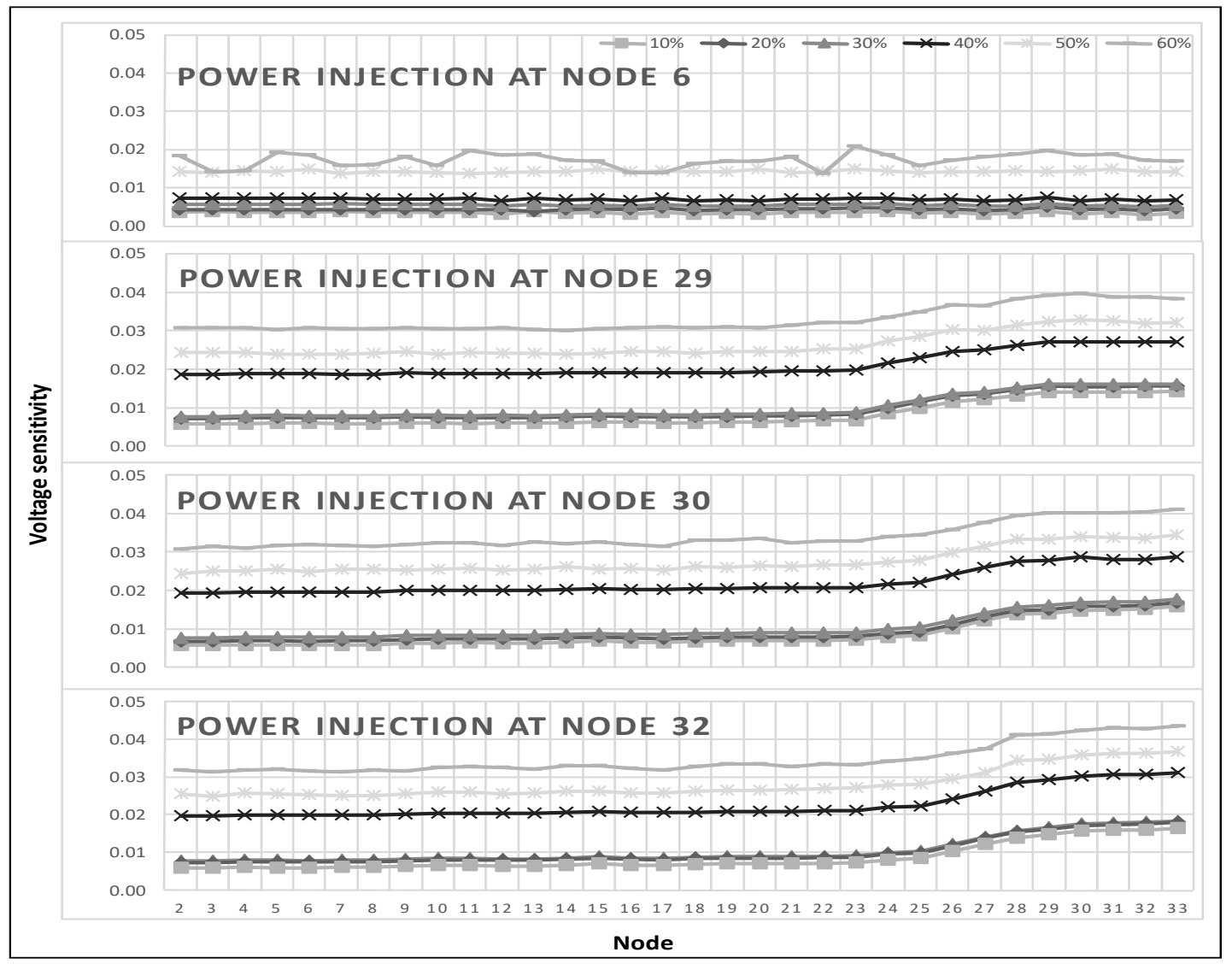

Figure 3. Voltage sensitivity analysis $\Delta \mathrm{V} / \Delta \mathrm{P}$ for the 33-node radial distribution network

Voltage sensitivity analysis to determine the optimal integration of distributed... (Katherine Cabana) 


\subsection{Sensitivity analysis of the 69-node test case}

Figure 4 presents the voltage sensitivity analysis of the nodes in the 69 -node radial distribution network. The real power was injected changing from $10 \%$ to $60 \%$ of the total load in steps of $10 \%$. The axis $y$ represents the change in voltage magnitude with respect to the change in real power injection. The nodes selected by the algorithms are 19, 25 and 68, and the node 7 was selected randomly to compare the voltage variations. Voltage magnitude variations are confirmed, especially when the generation is larger than $30 \%$ of the load. The voltage variations are similar for all nodes. When the penetration is higher the voltages are largely increased.

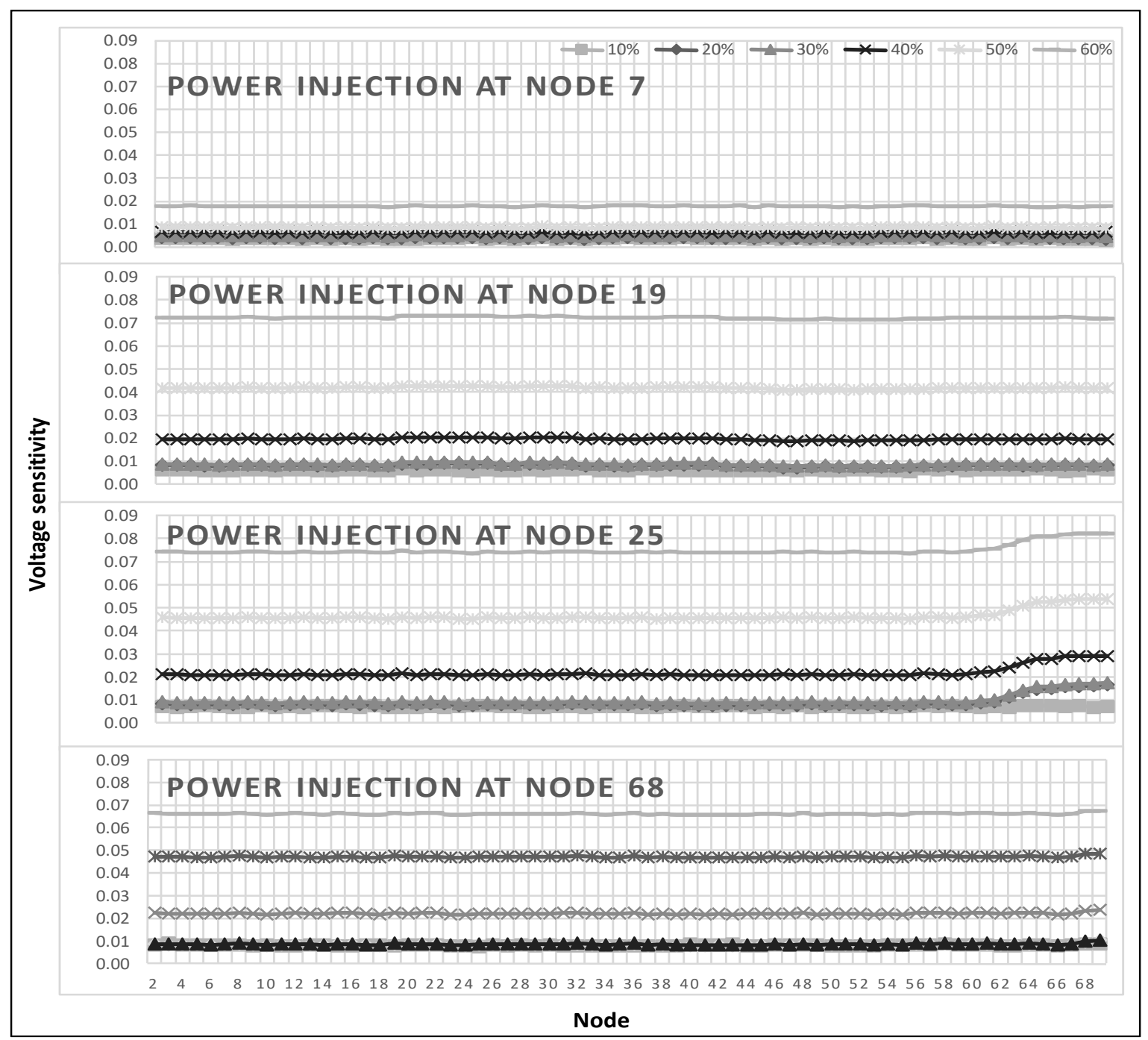

Figure 4. Voltage sensitivity analysis $\Delta \mathrm{V} / \Delta \mathrm{P}$ for the 69 -node radial distribution network

\subsection{Sensitivity analysis of the 118-node test case}

Figure 5 presents the voltage sensitivity analysis of the nodes in the 118 -node radial distribution network. The real power was injected changing from $10 \%$ to $60 \%$ of the total load in steps of $10 \%$. The axis $\mathrm{y}$ represents the voltage magnitude change with respect to the real power change. The axis $\mathrm{x}$ represents the node of the distribution network. The PSO and SA selected the nodes 21, 22 and 117. 


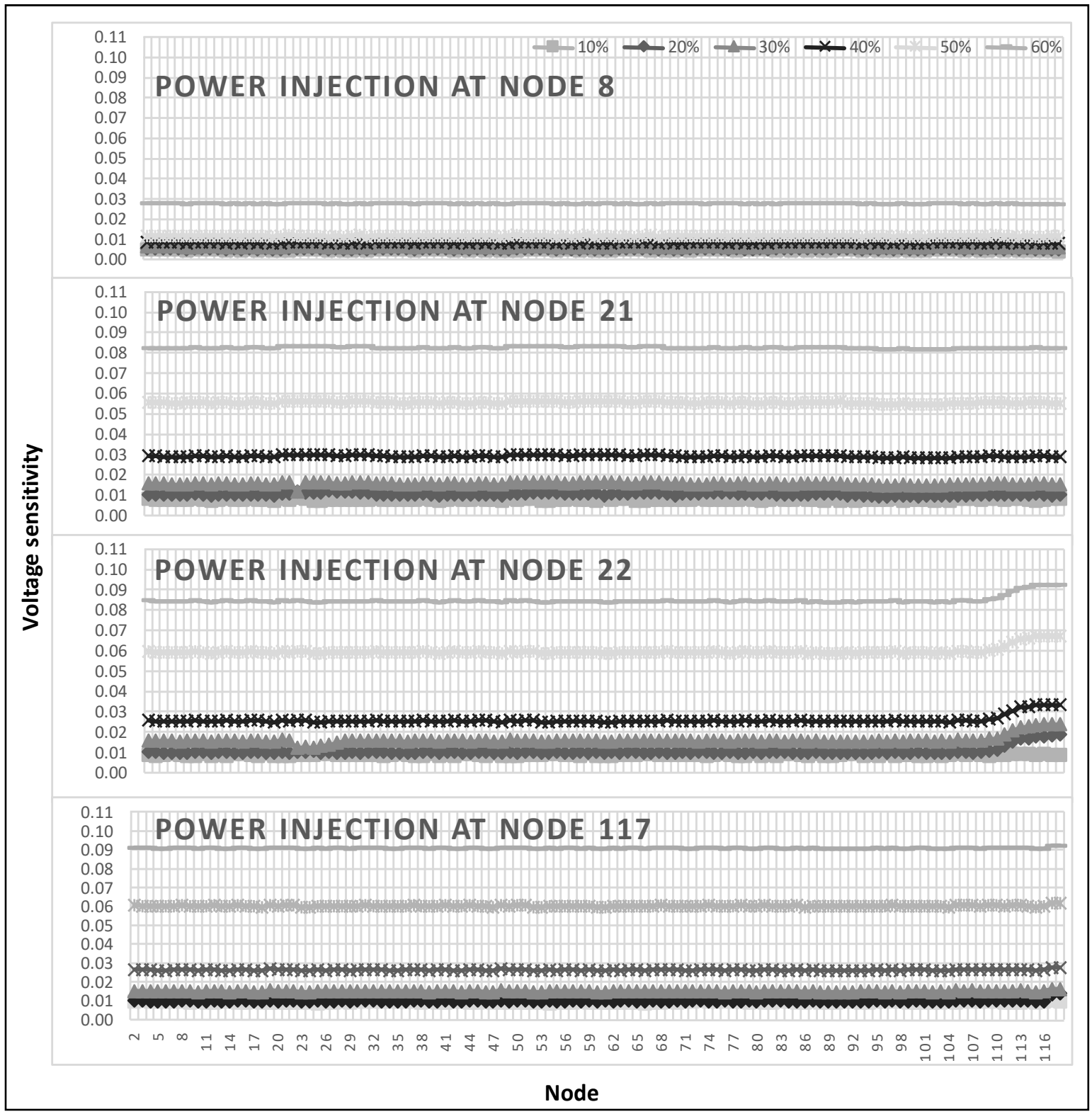

Figure 5. Voltage sensitivity analysis $\Delta \mathrm{V} / \Delta \mathrm{P}$ for the 118 -node radial distribution network

Additionally, the node 8 was selected to compare the results with the best nodes for the power injection. Similar to the previous results, the nodes selected show a high increase of voltage magnitudes, especially when the power injections are greater than $30 \%$ of the total load. The node 8 presents a low voltage changes after the power injections and the variation do not represent significant changes on voltage magnitudes of all nodes.

\section{CONCLUSION}

This article presented the placement and size of DG in distribution systems using voltage sensitivity analysis. PSO and SA were used in this research to identify the nodes that accept the maximum real power injections. The algorithms identified well the nodes for power injection, but PSO was faster than the SA. Nodes away from the main source can increase more the voltage magnitudes and are more likely to be selected with the model applied. The model presented in this paper showed how to place different types of DG in distribution systems to improve voltage profiles with a good percentage of success. The results of the simulations show the location and size of the injections of power to impact positively on the system. 
The model showed a good percentage of success when locating different types of DG to improve voltage magnitudes in the three distribution networks. Location and size of power sources impact positively the radial network and after repeating all the test the results were similar, although in all the analysis performed the PSO is faster than the SA.

\section{REFERENCES}

[1] P. Suresh Babu and R. Madhan Mohan, "Optimal Performance Enhancement of DG for Loss Reduction using Fuzzy and Harmony Search Algorithm," in 2015 International Conference on Electrical, Electronics, Signals, Communication and Optimization (EESCO), 2015, pp. 1-5.

[2] Y. O. Gummadi Srinivasa Rao, "Voltage Profile Improvement of Distribution System using Distributed Generating Units,” Int. J. Electr. Comput. Eng., vol. 3, no. 2088-8708, pp. 337-343, 2013.

[3] A. Yadav and L. Srivastava, "Optimal Placement of Distributed Generation: An Overview and Key Issues," in 2014 International Conference on Power Signals Control and Computations (EPSCICON), 2014, pp. 1-6.

[4] M. P.S. and S. Hemamalini, "Optimal Siting of Distributed Generators in a Distribution Network using Artificial Immune System,” Int. J. Electr. Comput. Eng., 2017.

[5] A. A. Abou El-Ela, A. M. Azmay, and A. A. Shammah, "Optimal Sitting and Sizing of Distributed Generations In Distribution Networks Using Heuristic Algorithm," in 2015 50th International Universities Power Engineering Conference (UPEC), 2015, pp. 1-7.

[6] and A. G. Hocine Ait-Saadi1, Jean-Yves Chouinard2, "A PAPR Reduction for OFDM Signals Based on SelfAdaptive Multipopulation DE algorithm Hocine," Int. J. Electr. Comput. Eng., 2017.

[7] R. S. Al Abri, E. F. El-Saadany, and Y. M. Atwa, "Optimal Placement and Sizing Method to Improve the Voltage Stability Margin in a Distribution System Using Distributed Generation,” IEEE Trans. Power Syst., vol. 28, no. 1, pp. 326-334, Feb. 2013.

[8] H. W. K. M. Amarasekara, L. Meegahapola, A. P. Agalgaonkar, and S. Perera, "Impact of Renewable Power Integration On VQ Stability Margin," in 2013 Australasian Universities Power Engineering Conference (AUPEC), 2013, pp. 1-6.

[9] R. S. Al Abri, "Voltage Stability Analysis With High Distributed Generation Penetration," Waterloo, 2012.

[10] L. Wei and Zhang Haiyan, "Allocation of Distributed Generations Based on Improved Particle Swarm Optimization Algorithm," Int. Conf. Meas. Inf. Control, 2013.

[11] W. S. Ke-yan Liu, Kaiyuan He, "Multiple-Objetive DG Optimal Sizing In Distribution System Using An Improverd PSO Algorith," IEEE Trans. Automat. Contr., pp. 1-4, 2013.

[12] S. S. Musa, H. ; Adamu, "Enhanced PSO Based Multi-Objective Distributed Generation Placement And Sizing For Power Loss Reduction And Voltage Stability Index Improvement," IEEE Trans. Automat. Contr., pp. 1-6, 2013.

[13] M. Shekeew, M. Elshahed, and M. Elmarsafawy, "Impact of Optimal Location, Size And Number Of Distributed Generation Units On The Performance Of Radial Distribution Systems," in 2016 IEEE 16th International Conference on Environment and Electrical Engineering (EEEIC), 2016, pp. 1-6.

[14] D. Jia, L. Hu, K. Liu, Y. Liu, X. Meng, and W. Sheng, "Simplified Probabilistic Voltage Stability Evaluation Considering Variable Renewable Distributed Generation In Distribution Systems," IET Gener. Transm. Distrib., vol. 9, no. 12, pp. 1464-1473, Sep. 2015.

[15] J. Silva et al., "A 75 Bus Bars Model To Evaluate The Steady State Operation Of A Sub-Transmission Electrical Power Grid," Espacios, 2016.

[16] K. Cabana, "Statistical Analysis of Voltage Sensitivity in Distribution Systems Integrating DG," IEEE Latin America Transactions. 2016.

[17] Z. Garcia Sánchez, J. A. González Cueto, G. Quintana de Basterra, and J. G. Boza Valerino, "Implementación de Un Estudio De Estabilidad De La Tensión Al Paquete De Programas Psx. 2.87," Ing. Energética, vol. 34, no. 1, pp. $33-42$.

[18] K. Morison, X. Wang, A. Moshref, and A. Edris, "Identification of Voltage Control Areas And Reactive Power Reserve; An Advancement In On-Line Voltage Security Assessment," in 2008 IEEE Power and Energy Society General Meeting - Conversion and Delivery of Electrical Energy in the 21st Century, 2008, pp. 1-7.

[19] R. A. Walling, R. Saint, R. C. Dugan, J. Burke, and L. A. Kojovic, "Summary of Distributed Resources Impact on Power Delivery Systems," IEEE Trans. Power Deliv., vol. 23, no. 3, pp. 1636-1644, Jul. 2008.

[20] H. Zeineldin, E. El-saadany, and M. A. Salama, "Distributed Generation Micro-Grid Operation: Control and Protection," in 2006 Power Systems Conference: Advanced Metering, Protection, Control, Communication, and Distributed Resources, 2006, pp. 105-111.

[21] P. C. Lu Zhang, Wei Tang, Muke Bai, "Analysis of Distributed Generation Influences On The Voltage Limit Violation Probability Of Distribution Line," Energy Power Eng., vol. 5, pp. 756-762, 2013.

[22] Y. M. Atwa, E. F. El-Saadany, M. M. A. Salama, and R. Seethapathy, "Optimal Renewable Resources Mix for Distribution System Energy Loss Minimization,” IEEE Trans. Power Syst., vol. 25, no. 1, pp. 360-370, Feb. 2010.

[23] Y. M. Atwa, E. F. El-Saadany, M. M. A. Salama, and R. Seethapathy, "Distribution System Loss Minimization Using Optimal DG Mix," in 2009 IEEE Power \& Energy Society General Meeting, 2009, pp. 1-6.

[24] M. H. Albadi and E. F. El-Saadany, "Novel Method For Estimating the CF of Variable Speed Wind Turbines," in 2009 IEEE Power \& Energy Society General Meeting, 2009, pp. 1-6.

[25] M. H. Albadi and E. F. El-Saadany, "Wind Turbines Capacity Factor Modeling\&\#x2014;A Novel Approach," IEEE Trans. Power Syst., vol. 24, no. 3, pp. 1637-1638, Aug. 2009. 
[26] P. Monzón, Artenstein Michel, and J. Alonso, "Evaluación De La Estabilidad De Tensión En Una Red De Potencia Con Base A Criterios Derivados De La Teoría De La Bifurcación Más Cercana," Aerosp. Eng. Control Syst. Eng. Electr. Eng., 2014.

[27] A. N. B. Alsammak, "Bifurcation and Voltage Collapse In The Electrical Power Systems," Al_Rafidain Eng., vol. vol.13, pp. 25-41, 2005.

[28] S. A. Taher and S. A. Afsari, "Optimal Location and Sizing of UPQC in Distribution Networks Using Differential Evolution Algorithm," Math. Probl. Eng., vol. 2012, 2012.

[29] M. E. Baran and F. F. Wu, "Network Reconfiguration In Distribution Systems For Loss Reduction And Load Balancing," IEEE Trans. Power Deliv., vol. 4, no. 2, pp. 1401-1407, Apr. 1989.

[30] P. Phonrattanasak and N. Leeprechanon, "Optimal Location of Fast Charging Station on Residential Distribution Grid - Volume 3 Number 6 (Dec. 2012) - IJIMT,” Int. J. Innov. Manag. Technol., vol. 3, no. 6, pp. 675-681, 2012.

[31] S. Sultana and P. K. Roy, "Multi-Objective Quasi-Oppositional Teaching Learning Based Optimization For Optimal Location Of Distributed Generator In Radial Distribution Systems," Int. J. Electr. Power Energy Syst., vol. 63, pp. 534-545, 2014.

\section{BIOGRAPHIES OF AUTHORS}

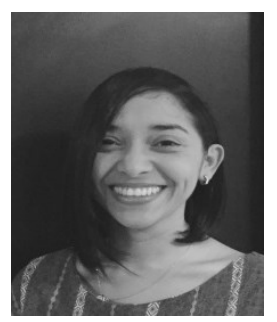

Katherine Cabana Jiménez received her Bs. degree in Electronic Engineering in 2008 and her MSc in Electrical Engineering in 2016 from Universidad del Norte, Barranquilla - Colombia. Her employment experiences include Universidad del Norte, and Universidad de la Costa CUC in Barranquilla - Colombia. Now, She is working as Professor of Universidad de la Costa CUC. Her research interests include engineering education and renewable resources. ORCID: 00000003-3859-1160.

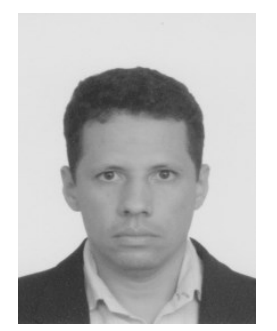

John Candelo Becerra received his Bs. degree in Electrical Engineering in 2002 and his $\mathrm{PhD}$ in Engineering with emphasis in Electrical Engineering in 2009 from Universidad del Valle, Cali Colombia.His employment experiences include the Empresa de Energía del Pacífico EPSA, Universidad del Norte, and Universidad Nacional de Colombia - Sede Medellín. He is now an Assistant Professor of the Universidad Nacional de Colombia - Sede Medellín, Colombia. His research interests include: engineering education; planning, operation and control of power systems; artificial intelligence; and smart grids. ORCID: 0000-0002-9784-9494.

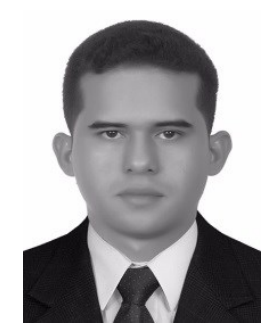

Rafael Castillo-Sierra was born in Barranquilla, Colombia in 1989. He received his Bs. degree in Electrical Engineering in 2012 and his M.Sc in Electrical Engineering in 2015 from Universidad del Norte, Barranquilla. He is currently working as Professor of the Universidad del Norte. His research interests include: High voltage insulation and Renewable energy. ORCID: 0000-00022648-4096.

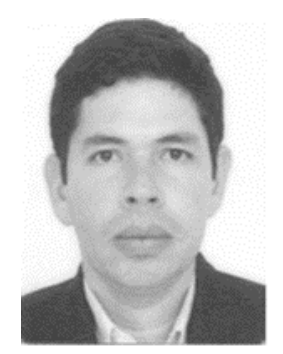

Emiro De la Hoz Franco has PhD degree in Technology of the Information and Communication (2016) and MSc degree in Systems Engineering and Networks in 2011 all from Granada University (Spain). Currently he is a full time professor and member of Software Engineering and Networks research group at Universidad de la Costa - CUC (Barranquilla, Colombia). His research interests are in the field of data mining and multiobjective optimization techniques. ORCID: 0000-0002-4926-7414. 